\title{
Mechanisms of disease
}

\section{Atrial fibrillation}

\section{George D. Veenhuyzen, Christopher S. Simpson, Hoshiar Abdollah}

\section{Abstract}

AtRIAL FIBRILLATION (AF) is the most common sustained dysrhythmia in adults. It is ironic, then, that although mechanisms and effective treatments for most other supraventricular tachyarrhythmias have been discovered, AF remains incompletely understood and poorly treated. Nonetheless, our understanding of the pathophysiology of AF has improved in the last half-century, including some groundbreaking observations made in the last 10 years. Indeed, for some patients, the potential for cure now appears to be available. Because no unifying mechanism of AF has been proven, the aim of this review is to describe some of the common and important concepts behind current mechanistic theories of AF and how they contribute to our clinical understanding of AF.

CMAJ 2004;171(7):755-60

\section{The science of atrial fibrillation}

Contemporary theories of the mechanism of atrial fibrillation require an understanding of re-entry as a mechanism of arrhythmogenesis. Re-entry, which is not a disorder of impulse formation but rather a disorder of impulse propagation, occurs when an impulse travels around an abnormal circuit repetitively. Consider 2 distinct areas of tissue (Fig. 1), where area $\mathrm{A}$ is excited by a depolarizing wavefront. Once excited, cells in area A cannot be excited again until their cell membranes have repolarized and the cells have recovered; the depolarizing wavefront has left the cells in its wake refractory to further stimulus. A premature stimulus activating area B cannot excite area $\mathrm{A}$ if it occurs when the intervening tissue is still refractory. However, if that depolarizing wavefront travels to area $\mathrm{A}$ by an alternate route, allowing sufficient time for tissue in area $\mathrm{A}$ to recover, then area $\mathrm{A}$ may be re-excited. Under the right circumstances, areas $\mathrm{A}$ and $\mathrm{B}$ can then re-excite each other, which leads to sustained "re-entry." Thus, re-entry requires an appropriately timed stimulus (trigger) that is able to find its way into a circuit (substrate) where its depolarizing wavefront never encounters refractory tissue.

In anatomic re-entry, the boundaries of the circuit are physical cardiac structures. An example of anatomic re-entry is also provided in Fig. 1, where an appropriately timed atrial premature beat (trigger) can initiate sustained re-entry in a right atrial circuit involving the isthmus between the inferior vena cava and the tricuspid valve annulus (substrate). Counterclockwise re-entry in this anatomically fixed circuit is the mecha- nism of typical atrial flutter. Repeated travel of an impulse around and around this circuit (with passive activation of the left atrium) produces ordered atrial activity that is observed electrocardiographically as sawtooth flutter waves. Alternatively, variations in the electrophysiologic properties of contiguous tissues, not anatomic obstacles, may serve as the boundaries of a functional re-entry circuit. While anatomic reentry is the mechanism of typical atrial flutter, functional reentry appears to be important in $\mathrm{AF}$.

\section{Functional re-entry and the leading circle model}

Several models of functional re-entry have been proposed. The "leading circle" model suggests that functional re-entry circuits naturally occupy the smallest possible circuit size, or wavelength. ${ }^{1}$ At a given conduction velocity, the size of the circuit will be the distance travelled in the shortest time required for refractory tissue to recover (wavelength = mean conduction velocity $\times$ refractory period). The circuit size could not possibly be smaller than the wavelength because that would require the depolarizing wavefront to collide with refractory tissue and extinguish itself: the leading end of the circle cannot "bite its own tail" (Fig. 2).

Since the 1960s, the most popular theory has held that AF consists of multiple wavelets of functional re-entry.' Stability in this model is derived from a critical number of wavelets, which travel throughout the atria, colliding, combining or dividing and thereby spawning daughter wavelets that perpetuate the process. Conditions that increase atrial size or decrease the wavelength (by decreasing the conduction velocity or refractory period or both) permit multiple wavelets and promote $\mathrm{AF}^{3}$ The results of some mapping studies of both animals and humans have been consistent with the presence of multiple reentrant wavelets that propagate in different directions. ${ }^{3-5}$

Although other models of functional re-entry, including the spiral wave model, ${ }^{6}$ have been proposed (and remain beyond the scope of this article), the "multiple wavelets" hypothesis has dominated contemporary thinking on the mechanism of AF. Because mapping studies in various models of AF have yielded different observations, and because of limitations in mapping resolution, proof of any one model has remained elusive.

In an important study, the inducibility, rate and duration of $\mathrm{AF}$ in an animal model were increased when $\mathrm{AF}$ was artificially maintained. ${ }^{7}$ By using a pacemaker capable of deliv- 


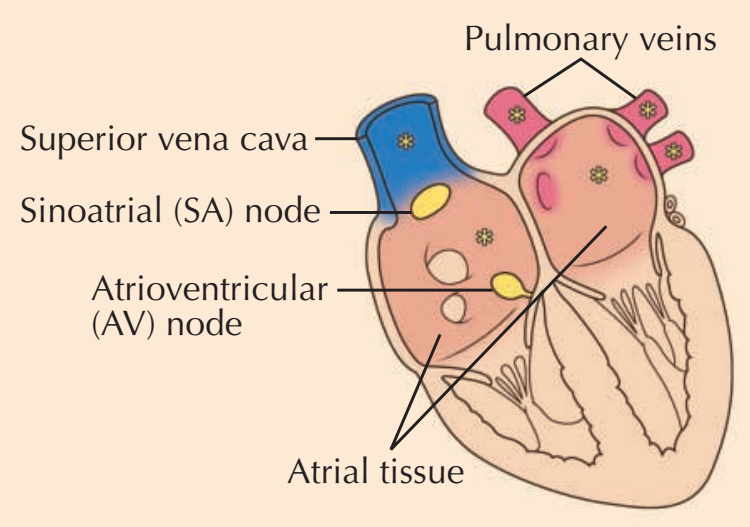

A

a)

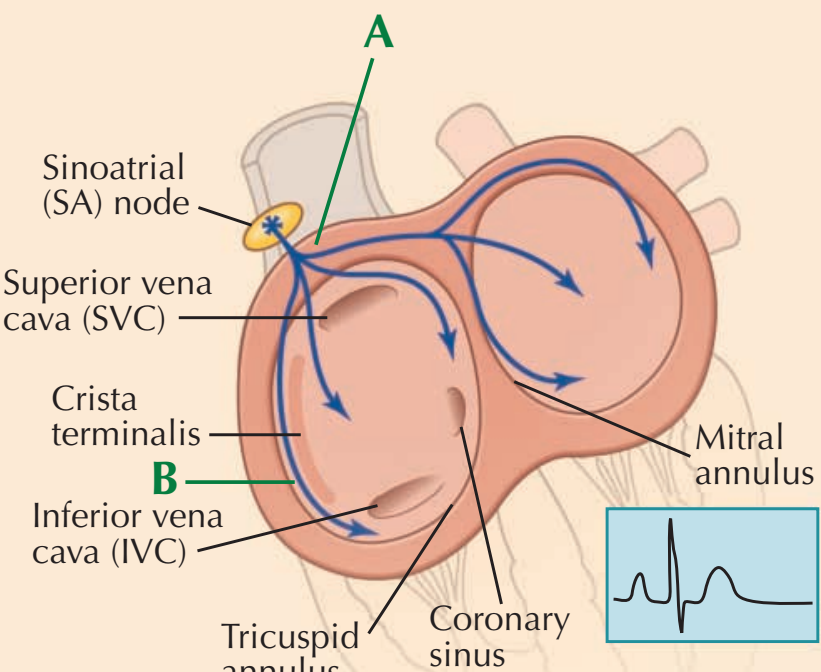

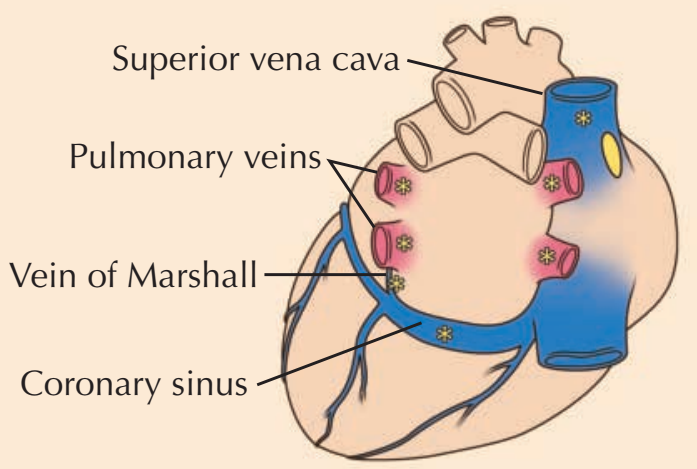

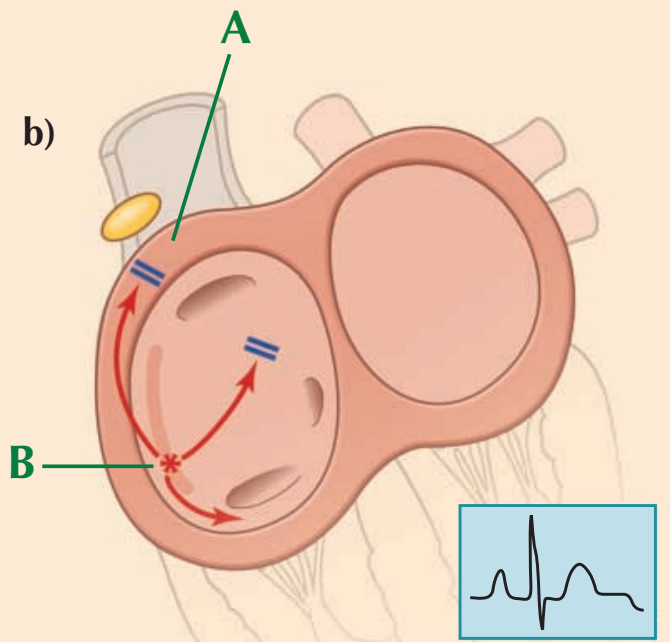

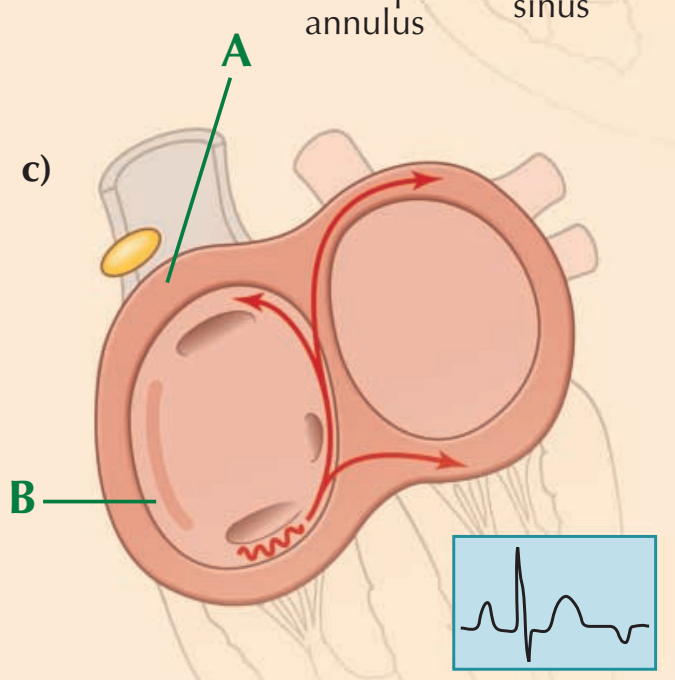

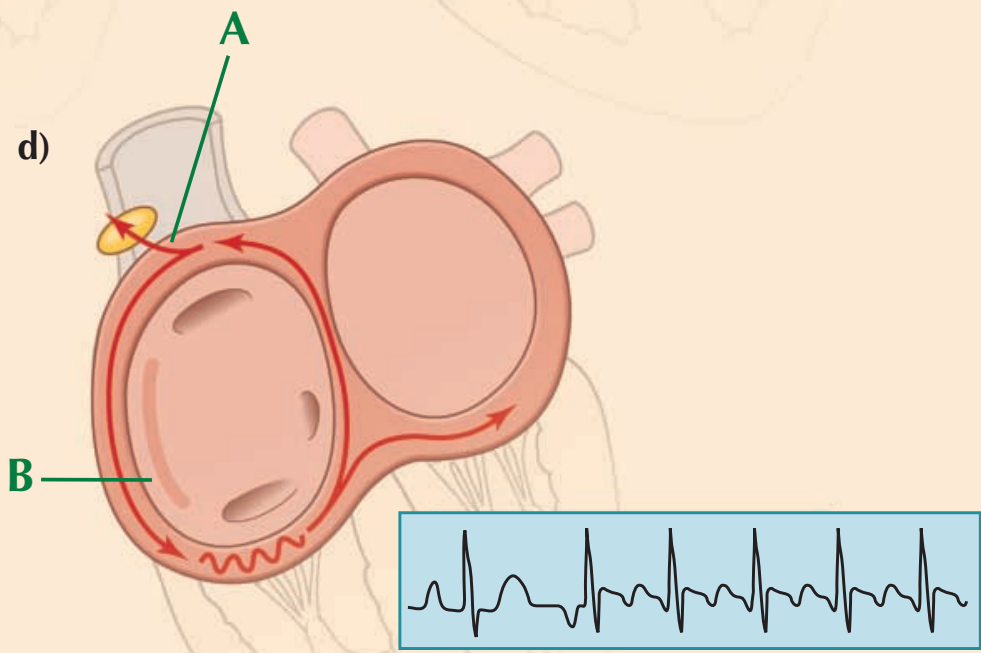

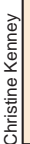

Fig. 1: Re-entry. a) A sinus impulse activates area A. b) A premature beat arising in area B fails to reach area A because the intervening tissue remains refractory from the preceding sinus beat. c) The premature stimulus travels slowly via an alternative route back to area A, allowing enough time for area A to recover and be excited. d) Area A re-excites area B, and the cycle sustains itself. This particular example illustrates the mechanism of typical atrial flutter. 
ering 1-second bursts of very rapid stimuli, nonsustained AF lasting only a few seconds could be induced. By repeatedly inducing (and thus maintaining) AF for 24 hours, bursts of induced AF lasted approximately 20 seconds. After 2 weeks of artificially maintained AF, it became sustained. Consistent with a model of functional re-entry, the perpetuation of $\mathrm{AF}$ was accompanied by a shortening of the atrial refractory period. The authors concluded that "AF begets AF": $\mathrm{AF}$ is capable of inducing electrophysiologic changes that promote further AF. These include electrical, contractile and structural changes to the atria that have collectively become known as atrial remodelling.

\section{Electrical remodelling}

When cardiac myocytes are excited, their resting membrane potential, which is polarized at about $-80 \mathrm{mV}$, becomes depolarized by an inward rush of positively charged ions, and the action potential begins (Fig. 3). Inward calcium currents cause the membrane potential to plateau, which contributes significantly to the action potential duration. At rapid atrial rates such as those during periods of fibrillation, the repeated inward calcium current significantly increases myocyte calcium load. Because high intracellular calcium concentrations can be toxic, adaptive mechanisms rapidly reduce the load to protect the cell. Early in the remodelling process, the membrane channel responsible for calcium entry becomes less active. ${ }^{8}$ Eventually, the production of that channel is downregulated. ${ }^{9}$ These changes ultimately reduce the inward calcium current, and this in turn reduces the action potential duration. If the action potential duration shortens, the refractory period shortens too, and the cell can be ready for reactivation earlier (Fig. 3). Hence, adaptive mechanisms that respond to intracellular calcium loads ulti- mately shorten the atrial refractory period, promoting functional re-entry and perpetuation of AF..$^{10}$ Even in the case of prolonged $\mathrm{AF}$, atrial electrical remodelling reverses quickly and completely once sinus rhythm is restored. ${ }^{11}$

\section{Contractile remodelling}

Atrial electrophysiologic changes induced by AF may have other, more widespread effects on myocyte function. For example, myofilament sliding, the cellular action responsible for muscle contraction, is intimately dependent upon intracellular calcium concentrations. Studies conducted on animals and humans have demonstrated AF-related reductions in atrial contractile function that were lessened by treatment with a calcium-channel antagonist or exaggerated by treatment with a calcium-channel agonist, which suggests that abnormal calcium handling at high rates may be responsible for remodelling. ${ }^{12,13} \mathrm{AF}$ also results in dedifferentiation of myocytes to fetal forms ${ }^{14,15}$ with cell architectures displaying reduced contractile elements and higher resistance to calcium-induced cell death. ${ }^{16}$ Thus, changes associated with AF contribute to the development of an atrial cardiomyopathy.

\section{Structural remodelling}

Another condition where cardiac remodelling has received considerable attention is heart failure. Here, the focus has been on describing the macro- and microscopic changes in ventricular myocardium that result from and contribute to systolic dysfunction. The frequent coexistence of $\mathrm{AF}$ and heart failure has expanded the focus to the atrial myocardium, where profibrillatory changes include conduction slowing associated with scarring and fibrosis and an increase in atrial size while refractory periods are actually increased. ${ }^{17}$

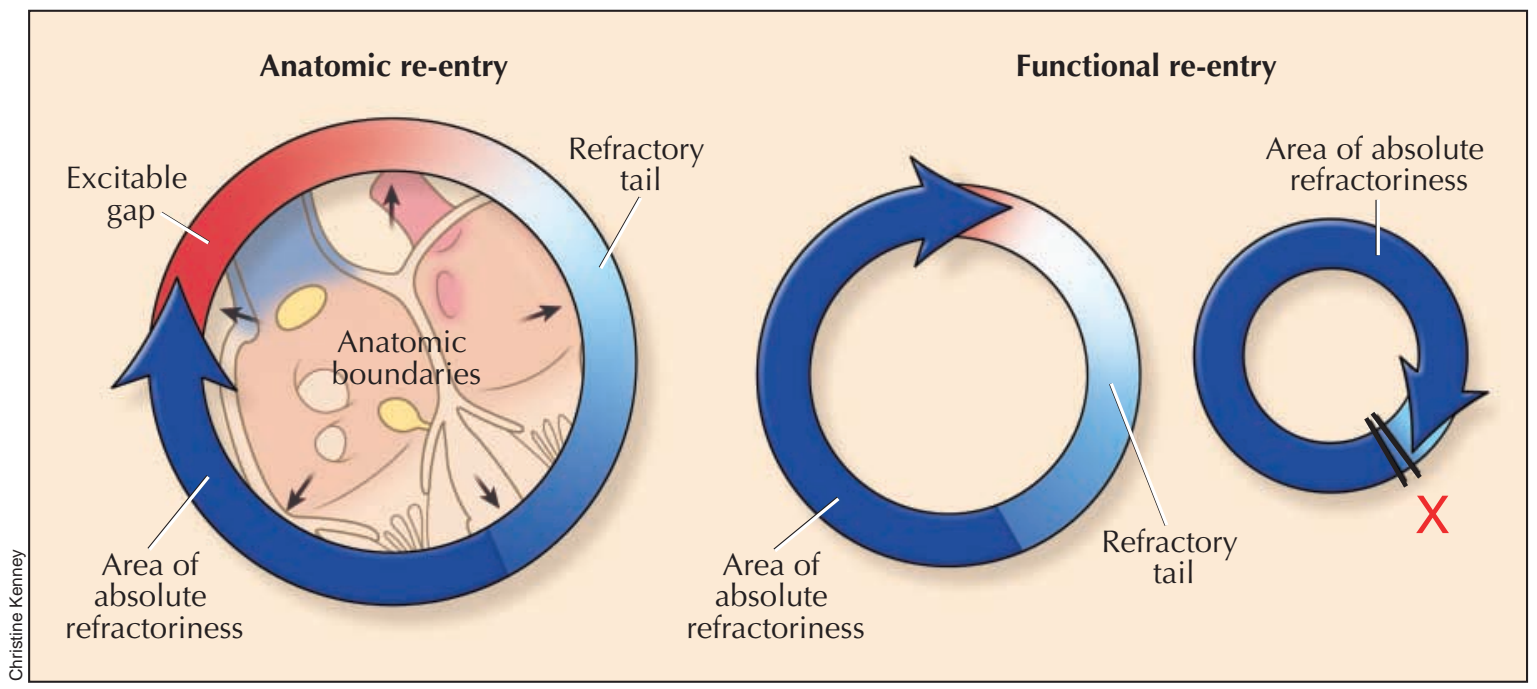

Fig. 2: Anatomic versus functional re-entry. In anatomical re-entry, circuit size is determined by fixed anatomic obstacles (left). In functional re-entry (middle), circuit size $=$ conduction velocity $\times$ refractory period (length of the refractory tail). If the wavefront travels too quickly, or its refractory period is too long, its leading end would "bite its tail" and extinguish itself (right). Thus, these properties determine the smallest possible circuit size. 
In a canine heart failure model, despite recovery of atrial electrical and contractile remodelling, AF remained inducible and appeared to be related to persistent atrial fibrosis. ${ }^{18}$ Patients with long-standing AF in the absence of heart failure also appear to have increased atrial fibrosis, ${ }^{19,20}$ but those with paroxysmal AF do not. ${ }^{21}$ Thus, chronicity may be important for this component of structural remodelling. In animals with long-standing AF, atrial fibrosis can be prevented by inhibition of the renin-angiotensin system, which appears to significantly reduce the duration of $\mathrm{AF}^{22}$

\section{The trigger: a focal origin}

Atrial remodelling, which prepares the atrium for multiple wavelets of functional re-entry, addresses the substrate for $\mathrm{AF}$, but what of the trigger? A landmark paper published in 1998 identified the muscular sleeve of the pulmonary veins as a source of tachyarrhythmias and atrial premature beats that could trigger paroxysms of AF. ${ }^{23} \mathrm{It}$ was later determined that in patients with frequent paroxysms of AF, the muscular sleeve of the pulmonary veins displays electrophysiologic properties (including shorter refractory periods) distinct from those of both the adjacent left atrial muscle and the muscular sleeve of the pulmonary veins in control subjects without $\mathrm{AF} ;{ }^{24}$ specialized conduction cells in the pulmonary veins have also been discovered. ${ }^{25}$ Although atrial tissue and the muscular sleeves of other cardiac veins, including the coronary sinus, ${ }^{26}$ the vein of $\mathrm{Marshall}^{27}$ and the superior vena cava, ${ }^{28,29}$ have been implicated as sources of tachyarrhythmias and $\mathrm{AF}$ triggering beats, none do so with nearly the frequency of the pulmonary veins. The proposed mechanisms for these "focal" tachyarrhythmias (micro-re-entry v. disorders of impulse formation) are reviewed elsewhere. ${ }^{30}$

The demonstration of focal tachyarrhythmias in patients with paroxysmal $\mathrm{AF}$ has challenged the multiple wavelet hypothesis. A competing theory now suggests that focal tachy-

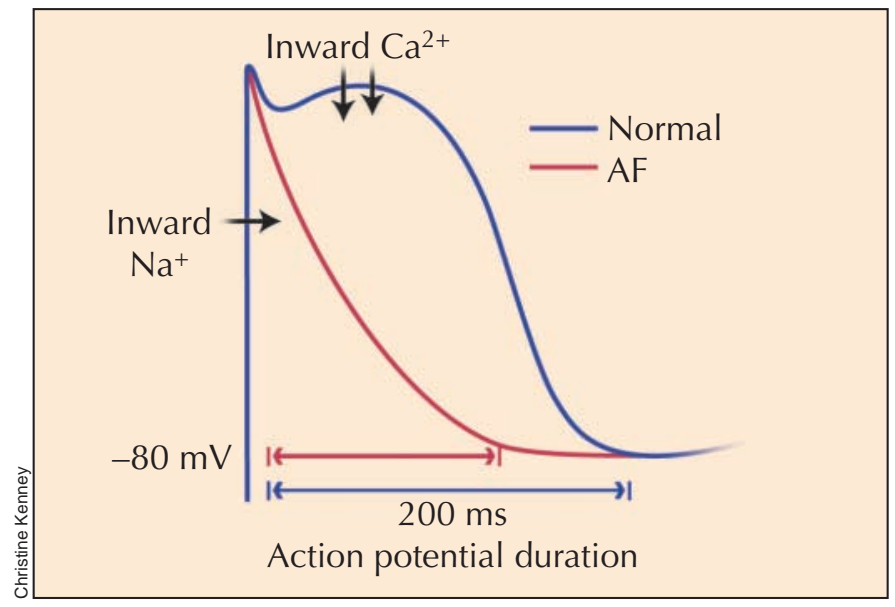

Fig. 3: Action potential duration: normal versus after atrial fibrillation. The action potential duration and refractory period are shortened as the calcium current is reduced. arrhythmias may be the sole underlying rhythm that drives $\mathrm{AF}$. In a canine AF model, Morillo and colleagues demonstrated the presence of a tachyarrhythmia originating in the pulmonary vein region that was faster than any in other parts of the atria and that responded to catheter ablation. ${ }^{31}$ In animal models, electroanatomic ${ }^{32}$ and optical ${ }^{33}$ mapping have demonstrated complex wavefronts within or emanating from the pulmonary veins. Thus, focal discharges may not simply be the triggers for multiple wavelet re-entry. The relative contribution of these 2 competing mechanisms in explaining $\mathrm{AF}$ in populations with and without structural heart disease remains largely unknown. In animal models, the persistence of AF after sufficient rapid atrial pacing implies a significant relationship between a focal driver (pacing) and the development of AF. Thus, a unifying theory is that focal tachycardias (which originate mostly in or around the pulmonary veins) promote atrial remodelling and are required to trigger and maintain a substrate capable of multiple wavelet reentry.

\section{The clinical context}

On an electrocardiogram, AF is characterized by a chaotic undulating baseline without evidence of regular, organized atrial activity. One can imagine how multiple wavelets of functional re-entry meandering around the atria could produce this appearance. Alternatively, a very rapid focal driver of AF could also produce irregular atrial activity if conduction spreading away from that source was irregular. For instance, if certain parts of the atria were capable of 1:1 conduction and others were not, an irregular pattern of atrial activation ("fibrillatory conduction") could obscure the regularity of the underlying focus. Hence, both of the major mechanistic theories of $\mathrm{AF}$ are capable of explaining its well-known electrocardiographic features.

Interventions that decrease atrial size or prolong atrial refractoriness should impair multiple wavelet re-entry and serve to both terminate $\mathrm{AF}$ and maintain sinus rhythm. The Maze procedure, in which the atria are surgically divided into smaller components that are potentially incapable of sustaining multiple re-entrant wavelets, is highly effective in restoring and maintaining sinus rhythm. ${ }^{34}$ Antiarrhythmic drugs used in rhythm control strategies prolong atrial refractoriness and increase the circuit size (wavelength), which theoretically leads to a reduction in the number of re-entrant wavelets that can be supported. However, the salutary effects of some antiarrhythmic drugs cannot be explained by the leading circle model, since increased refractory periods are compensated for by a reduction in conduction velocity, such that the wavelength does not lengthen. ${ }^{4}$

The likelihood that AF will terminate, either spontaneously or as a result of a medical intervention, is inversely related to the duration of the episode. This clinical observation mirrors the experimental adage that "AF begets $\mathrm{AF}$," which is founded in cellular mechanisms of atrial remodelling. Pretreatment with a calcium-channel blocker reduces early recurrences of $\mathrm{AF}$ after cardioversion, which empha- 
sizes the remodelling process itself as a novel therapeutic target. ${ }^{35}$ Because electrical remodelling resolves rather quickly, it cannot explain late recurrences of $\mathrm{AF}$ after cardioversion. Furthermore, the frequent association of $\mathrm{AF}$ with structural heart disease emphasizes the clinical significance of structural remodelling. Along these lines, use of renin-angiotensin system inhibitors has been associated with a reduction in the incidence of $\mathrm{AF}$ among patients with a myocardial infarction or impaired left ventricular systolic function and among patients receiving amiodarone who have undergone elective cardioversion..$^{36-38}$ Thus, angiotensin receptor blockers and angiotensin-converting-enzyme inhibitors are an attractive therapeutic option for people who have hypertension and $\mathrm{AF}$. The strategy of treating normotensive AF with an angiotensin receptor blocker is currently being tested in a randomized trial (Dr. Stuart Connolly, Professor of Medicine, McMaster University: personal communication, 2004).

Contractile remodelling induced by $\mathrm{AF}$ may be responsible for its most devastating consequence: stroke. Impaired atrial contraction leading to stasis of blood, primarily in the left atrial appendage, is thought to be the major contributor to the development of thrombi that may embolize. The persistence of atrial stunning for several weeks after the restoration of sinus rhythm explains why strokes can develop within this pe$\operatorname{riod}^{39,40}$ and is the basis for current guidelines that recommend continued anticoagulation after successful cardioversion. ${ }^{41}$

Perhaps the most important clinical implication of a focal mechanism is the prospect of a cure for selected patients with AF. The dominant mechanistic proposal suggests that strategies that electrically insulate (or "isolate") the musculature of the pulmonary veins from the left atrium serve to prevent tachyarrhythmias located in the pulmonary vein region from

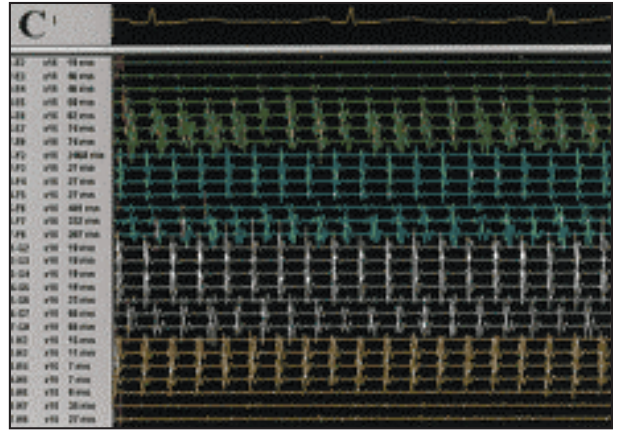

Fig. 4: A fibrillating isolated pulmonary vein. The top tracing is a single-surface-lead electrocardiogram tracing (at a faster-than-usual paper speed). The tracings underneath are recorded from inside the pulmonary vein of a patient who is undergoing a catheter-based procedure for paroxysmal atrial fibrillation. Note that the vein is fibrillating, but the heart is in normal sinus rhythm. The fibrillating pulmonary venous musculature has been "isolated" from the rest of the heart. [Reproduced, with permission, from reference 42.] conducting out to the atria. Thus, tachyarrhythmias or triggering premature beats can be confined to the pulmonary veins (Fig. 4). Atrial divisions that are produced by the Maze procedure achieve this goal and possibly offer a different explanation for the success of surgery. Catheter-based procedures, which continue to evolve, have effected freedom from symptomatic $\mathrm{AF}$, at least in the short term, in $60 \%-80 \%$ of selected patients with paroxysmal $\mathrm{AF}$ and $25 \%-70 \%$ of selected patients with persistent $\mathrm{AF}^{43,44}$ Because of a small risk of serious complications, including pulmonary vein stenosis and stroke, and because long-term follow-up studies are lacking, these procedures are usually reserved for symptomatic patients whose paroxysmal AF has proven refractory to antiarrhythmic drugs. The modest efficacy of antiarrhythmic drugs combined with their potential for side effects, toxic effects on organs and proarrhythmia have generated enthusiasm for catheter-based approaches. Accordingly, randomized trials comparing their efficacy and safety are already underway. ${ }^{45}$ As data from follow-up studies of patients who have undergone catheter-based procedures accrue, assessment of their long-term efficacy will emerge.

\section{The future}

Two competing theories of the mechanism of AF predominate: multiple re-entrant wavelets versus a focal driver with fibrillatory conduction. Both mechanisms may actually be involved. The recent discovery of focal tachyarrhythmias in patients with $\mathrm{AF}$ has advanced our knowledge of the mechanism of $\mathrm{AF}$ in humans and shifted the therapeutic paradigm from drugs aimed at the substrate to catheter-based treatments aimed at the trigger. Accordingly, the therapeutic focus is increasingly on cure, rather than just on control.

Many questions remain. Why are cardiac veins, especially the pulmonary veins, so arrhythmogenic? What is the mechanism of these focal tachyarrhythmias, and what is the best strategy for dealing with them? What is the precise relation between substrate and trigger? Is remodelling the explanation for the inferior response of persistent $\mathrm{AF}$ to catheter ablation, or are there other mechanisms at play, such as secondary drivers in the posterior left atrium? As our understanding of the molecular mechanisms of remodelling improves, will the focus once again shift to novel drug therapies aimed at prevention? What therapeutic targets will emerge as a better understanding of the roles of genetics, inflammation, the autonomic nervous system and endothelial dysfunction develops?

Atrial fibrillation has often been referred to as the "last great frontier" in cardiac electrophysiology. Continued refinements in our understanding of its mechanisms will change that, enhancing the efficacy of therapy and ultimately improving the lives of our patients.

This article has been peer reviewed.

The authors are from the Division of Cardiology (Arrhythmia Service), Queen's University, Kingston, Ont.

Competing interests: None declared. 
Contributors: George Veenhuyzen drafted the article. All authors revised the manuscript critically for important intellectual content, contributed to the concept and design of the manuscript and gave final approval of the version submitted to be published.

Acknowledgement: We wish to thank Dr. D. George Wyse for his assistance in the review of this manuscript.

\section{References}

1. Allessie MA, Bonke FI, Schopman FJ. Circus movement in rabbit atrial muscle as a mechanism of tachycardia. III. The "leading circle" concept: a new model of circus movement in cardiac tissue without the involvement of an anatomical obstacle. Circ Res 1977;41(1):9-18.

2. Moe GK, Rheinboldt WC, Abildskov JA. A computer model of atrial fibrillation. Am Heart 7 1964;67:200-20.

3. Rensma PL, Allessie MA, Lammers WJ, Bonke FI, Schalij MJ. Length of excitation wave and susceptibility to reentrant atrial arrhythmias in normal conscious dogs. Circ Res 1988;62(2):395-410.

4. Konings KT, Kirchhof CJ, Smeets JR, Wellens HJ, Penn OC, Allessie MA. High-density mapping of electrically induced atrial fibrillation in humans. Circulation 1994;89(4):1665-80.

5. Cox JL, Canavan TE, Schuessler RB, Cain ME, Lindsay BD, Stone C, et al. The surgical treatment of atrial fibrillation. II. Intraoperative electrophysiologic mapping and description of the electrophysiologic basis of atrial flutter and atrial fibrillation. 7 Thorac Cardiovasc Surg 1991;101(3):406-26.

6. Pertsov AM, Davidenko JM, Salomonsz R, Baxter WT, Jalife J. Spiral wave of excitation underlie reentrant activity in isolated cardiac muscle. Circ Res 1993;72(3):631-50

7. Wijffels MC, Kirchhof CJ, Dorland R, Allessie MA. Atrial fibrillation begets atrial fibrillation. A study in awake chronically instrumented goats. Circulation 1995;92(7):1954-68.

8. Courtemanche M, Ramirez RJ, Nattel S. Ionic mechanisms underlying human atrial action potential properties: insights from a mathematical model. Am 7 Physiol 1998;275(1 Pt 2):H301-21.

9. Lai LP, Su MJ, Lin JL, Lin FY, Tsai CH, Chen YS, et al. Down-regulation of L-type calcium channel and sarcoplasmic reticular $\mathrm{Ca}(2+)$-ATPase mRNA in human atrial fibrillation without significant change in the mRNA of ryanodine receptor, calsequestrin and phospholamban: an insight into the mechanism of atrial electrical remodeling. 7 Am Coll Cardiol 1999;33(5):1231-7.

10. Gaspo R, Bosch RF, Talajic M, Nattel S. Functional mechanisms underlying tachycardia-induced sustained atrial fibrillation in a chronic dog model. Circulation 1997;96(11):4027-35

11. Yu WC, Lee SH, Tai CT, Tsai CF, Hsieh MH, Chen CC, et al. Reversal of atrial electrical remodeling following cardioversion of long-standing atrial fibrillation in man. Cardiovasc Res 1999;42(2):470-6.

12. Leistad E, Aksnes G, Verburg E, Christensen G. Atrial contractile dysfunction after short-term atrial fibrillation is reduced by verapamil but increased by BAY K8644. Circulation 1996;93(9):1747-54.

13. Daoud EG, Marcovitz P, Knight BP, Goyal R, Man KC, Strickberger SA, et al. Short-term effect of atrial fibrillation on atrial contractile function in humans. Circulation 1999;99(23):3024-7.

14. Ausma J, Wijffels M, van Eys G, Koide M, Ramaekers F, Allessie M, et al. Dedifferentiation of atrial cardiomyocytes as a result of chronic atrial fibrillation. Am 7 Pathol 1997;151(4):985-97.

15. Ausma J, Wijffels M, Thone F, Wouters L, Allessie M, Borgers M. Structural changes of atrial myocardium due to sustained atrial fibrillation in the goat Circulation 1997;96(9):3157-63.

16. Chizzonite RA, Zak R. Calcium-induced cell death: susceptibility of cardiac myocytes is age-dependent. Science 1981;213(4515):1508-11.

17. Sanders P, Morton JB, Davidson NC, Spence SJ, Vohra JK, Sparks PB, et al. Electrical remodeling of the atria in congestive heart failure: electrophysiological and electroanatomic mapping in humans. Circulation 2003;108(12):1461-8.

18. Cha TJ, Ehrlich JR, Zhang L, Shi YF, Tardif JC, Leung TK, et al. Dissociation between ionic remodeling and ability to sustain atrial fibrillation during recovery from experimental congestive heart failure. Circulation 2004;109(3):412-8.

19. Aime-Sempe C, Folliguet T, Rucker-Martin C, Krajewska M, Krajewska S, Heimburger M, et al. Myocardial cell death in fibrillating and dilated human right atria. 7 Am Coll Cardiol 1999;34(5):1577-86.

20. Davies MJ, Pomerance A. Pathology of atrial fibrillation in man. Br Heart 7 1972;34(5):520-5

21. Todd DM, Skanes AC, Guiraudon G, Guiraudon C, Krahn AD, Yee R, et al. Role of the posterior left atrium and pulmonary veins in human lone atria fibrillation: electrophysiological and pathological data from patients undergoing atrial fibrillation surgery. Circulation 2003;108(25):3108-14.

22. Kumagai K, Nakashima H, Urata H, Gondo N, Arakawa K, Saku K. Effects of angiotensin II type 1 receptor antagonist on electrical and structural remodeling in atrial fibrillation. 7 Am Coll Cardiol 2003;41(12):2197-204.

23. Haissaguerre M, Jais P, Shah DC, Takahashi A, Hocini M, Quiniou G, et al. Spontaneous initiation of atrial fibrillation by ectopic beats originating in the pulmonary veins. N Engl 7 Med 1998;339(10):659-66.

24. Jais P, Hocini M, Macle L, Choi KJ, Deisenhofer I, Weerasooriya R, et al.
Distinctive electrophysiological properties of pulmonary veins in patients with atrial fibrillation. Circulation 2002;106(19):2479-85.

25. Perez-Lugones A, McMahon JT, Ratliff NB, Saliba WI, Schweikert RA, Marrouche NF, et al. Evidence of specialized conduction cells in human pulmonary veins of patients with atrial fibrillation. 7 Cardiovasc Electrophysiol 2003;14(8):803-9.

26. Jais P, Haissaguerre M, Shah DC, Chouairi S, Gencel L, Hocini M, et al. A focal source of atrial fibrillation treated by discrete radiofrequency ablation. Circulation 1997;95(3):572-6.

27. Hwang C, Wu TJ, Doshi RN, Peter CT, Chen PS. Vein of marshall cannulation for the analysis of electrical activity in patients with focal atrial fibrillation. Circulation 2000;101(13):1503-5.

28. Shah DC, Haissaguerre M, Jais P, Clementy J. High-resolution mapping of tachycardia originating from the superior vena cava: evidence of electrical heterogeneity, slow conduction, and possible circus movement reentry. 7 Cardiovasc Electrophysiol 2002;13(4):388-92.

29. Tsai CF, Tai CT, Hsieh MH, Lin WS, Yu WC, Ueng KC, et al. Initiation of atrial fibrillation by ectopic beats originating from the superior vena cava: electrophysiological characteristics and results of radiofrequency ablation. Circulation 2000;102(1):67-74.

30. Nattel S. Basic electrophysiology of the pulmonary veins and their role in atrial fibrillation: precipitators, perpetuators, and perplexers. 7 Cardiovasc Electrophysiol 2003;14(12):1372-5

31. Morillo CA, Klein GJ, Jones DL, Guiraudon CM. Chronic rapid atrial pacing. Structural, functional, and electrophysiological characteristics of a new model of sustained atrial fibrillation. Circulation 1995;91(5):1588-95.

32. Okuyama Y, Miyauchi Y, Park AM, Hamabe A, Zhou S, Hayashi H, et al. High resolution mapping of the pulmonary vein and the vein of Marshall during induced atrial fibrillation and atrial tachycardia in a canine model of pacing-induced congestive heart failure. 7 Am Coll Cardiol 2003;42(2):348-60.

33. Kalifa J, Jalife J, Zaitsev AV, Bagwe S, Warren M, Moreno J, et al. Intra-atrial pressure increases rate and organization of waves emanating from the superior pulmonary veins during atrial fibrillation. Circulation 2003;108(6):668-71.

34. Cox JL, Boineau JP, Schuessler RB, Kater KM, Ferguson TB Jr, Cain ME, et al. Electrophysiologic basis, surgical development, and clinical results of the maze procedure for atrial flutter and atrial fibrillation. Adv Card Surg 1995;6:1-67.

35. De Simone A, Stabile G, Vitale DF, Turco P, Di Stasio M, Petrazzuoli F, et al. Pretreatment with verapamil in patients with persistent or chronic atrial fibrillation who underwent electrical cardioversion. 7 Am Coll Cardiol 1999;34(3):810-4.

36. Madrid AH, Bueno MG, Rebollo JM, Marin I, Pena G, Bernal E, et al. Use of irbesartan to maintain sinus rhythm in patients with long-lasting persistent atrial fibrillation: a prospective and randomized study. Circulation 2002;106(3):331-6.

37. Pedersen OD, Bagger H, Kober L, Torp-Pedersen C. Trandolapril reduces the incidence of atrial fibrillation after acute myocardial infarction in patients with left ventricular dysfunction. Circulation 1999;100(4):376-80.

38. Vermes E, Tardif JC, Bourassa MG, Racine N, Levesque S, White M, et al Enalapril decreases the incidence of atrial fibrillation in patients with left ventricular dysfunction: insight from the Studies Of Left Ventricular Dysfunction (SOLVD) trials. Circulation 2003;107(23):2926-31.

39. Missault L, Jordaens L, Gheeraert P, Adang L, Clement D. Embolic stroke after unanticoagulated cardioversion despite prior exclusion of atrial thrombi by transoesophageal echocardiography. Eur Heart 7 1994;15(9):1279-80.

40. Dunn MI, Marcum JL. Atrial mechanical performance following internal and external cardioversion of atrial fibrillation: its relationship to peripheral embolization and acute cerebrovascular accident. Chest 2002;121(1):1-3.

41. Fuster V, Ryden LE, Asinger RW, Cannom DS, Crijns HJ, Frye RL, et al; American College of Cardiology; American Heart Association; European Society of Cardiology; North American Society of Pacing and Electrophysiology. ACC/AHA/ESC guidelines for the management of patients with atrial fibrillation. A report of the American College of Cardiology/American Heart Association Task Force on Practice Guidelines and the European Society of Cardiology Committee for Practice Guidelines and Policy Conferences (Committee to develop guidelines for the management of patients with atrial fibrillation) developed in collaboration with the North American Society of Pacing and Electrophysiology. Eur Heart 7 2001;22(20):1852-923.

42. Sanchez JS, Plumb VJ, Epstein AD, Kay GN. Evidence for longitudinal and transverse fiber conduction in human pulmonary veins: relevance for catheter ablation. Circulation 2003;108(5);590-7.

43. Oral H, Ozaydin M, Tada H, Chugh A, Scharf C, Hassan S, et al. Mechanistic significance of intermittent pulmonary vein tachycardia in patients with atrial fibrillation. 7 Cardiovasc Electrophysiol 2002;13(7):645-50.

44. Pappone C, Oreto G, Rosanio S, Vicedomini G, Tocchi M, Gugliotta F, et al Atrial electroanatomic remodeling after circumferential radiofrequency pulmonary vein ablation: efficacy of an anatomic approach in a large cohort of patients with atrial fibrillation. Circulation 2001;104(21):2539-44.

45. Shah D. Curative ablation for atrial fibrillation: What clinical trials do we need to establish efficacy? 7 Cardiovasc Electrophysiol 2003;14(9 Suppl):S48-51.

Correspondence to: Dr. George D. Veenhuyzen, Assistant Professor, Department of Medicine, Queen's University, Fraser Armstrong Patient Centre 319, 76 Stuart St., Kingston ON K7L 2V7 